lege Library, 231 W. Hancock St., Milledgeville, GA 31061.

Proposals for programs at the National Conference are also welcome. Possible formats include panel presentations, discussion group sessions, idea briefs, or poster sessions. Programs may be either 30 or 60 minutes in length. Presenters must attend the conference at their own expense. Additional information will be sent upon the receipt of a program proposal.
Program proposals should include a 200-word description of the program, the tentative title, and name, mailing address, and work phone number of the contact person. The deadline for submitting a program proposal is July 31, 1988. Send program proposals to: ACRL Program, c/o Jordan Scepanski, University Library and Learning Resources, California State University, Long Beach, 1250 Bellflower Boulevard, Long Beach, CA 90840 .

\title{
Information for administrators
}

\author{
By Peter G. Watson \\ University Librarian \\ Idaho State University
}

\section{Report of a test of library information support for a neglected user group.}

\begin{abstract}
M ost academic libraries possess well-developed services to support the teaching, learning, and research functions of both students and faculty, yet offer no comparable support to the administrative function, which is obviously an activity highly crucial to the health and well-being of any college or university. Without dwelling on the reasons why this gap has been allowed to exist, this report will present some findings from one library's attempt to determine through a practical test, whether or not the library could in fact provide direct information support for campus administrators.

Picking up on the insights expressed by a librarian who is now an academic administrator (Rebecca Kellogg, University of Arizona), the Meriam Library of California State University, Chico, last academic year decided to devote a small amount of physical and personnel resources to seeing what would result if the Library offered the services of a librarian as an information assistant to administra-
\end{abstract}

tors, specifically to support the performance of their administrative duties. Evidence exists that librarians will have to a) make an attempt to understand the dynamics of the administrator's worklife; and b) be flexible about modes of library service, if they are to be successful in serving this group. ${ }^{1}$

Strong administrative support was given by CSU Chico's university librarian Judith A. Sessions, who wrote an introductory letter to the six senior administrators of the campus designating me-I was then assistant university librarian (programs and services) - as the agent to carry out the test. I visited the offices of those administrators, explained the concept and general procedures, and took copious notes.

${ }^{1}$ Rebecca Kellogg, "From the President," RQ 25 (Fall 1985):9-10; and Rebecca Kellogg," "Beliefs and Realities," C $b R L$ News 47 (September 1986):492-96. 
It is not my intention here to dwell on the procedural aspects of the operation, since there was nothing very remarkable or innovative about the actual searching. I merely did for the requesters what I would have done for myself, had the questions been my own: find the information. Using both computerized and manual tools, I searched through some secondary sources, identified some relevant-looking primary sources, and obtained working copies thereof. Computerized bibliographies, photocopies from paper or microform publications, and occasionally the telephone were the means used to respond to the administrators. Not surprisingly, the requests concerned such topics as academic program planning and management, degree standards, admission of special student groups, faculty salary comparisons, and recent affirmative action rulings.

At the end of the academic year a brief questionnaire was sent to the six individuals who had generated the 15 information requests. Five people responded, accounting for 12 of the requests.

Questions 1-3 employed a rating scale of 0-5 (least to most). Question 1 asked respondents how useful was the information supplied; Question 2 asked for their assessment of the timeliness of the library's response; and Question 3 asked, "How well did you feel the librarian understood your request?" The responses are shown in Table 1.

Question 4 asked whether there were any improvements in this service that would increase its usefulness. The four comments received were: "a great job-no improvement needed," "no," "I feel that it is an excellent opportunity that should run on a request basis," and "an outstanding service for the busy executive."

Question 5 inquired about their need for this type of service on a permanent basis. Here the responses were less one-sided, with three people checking Yes and two checking No. All who checked Yes also answered Yes to the follow-up question: would they be willing to have their account charged for the out-of-pocket costs? For those who checked No to Question 5, the follow-up question asked if there were some other kind of individually tailored information service that they were using or would like to see the Library provide.

\section{TABLE 1}

Responses to Questions 1-3

\begin{tabular}{crrrr}
\hline \hline Score & Frequency: & Q.1 & Q.2 & Q.3 \\
\hline 0 & & 0 & 0 & 0 \\
1 & & 1 & 0 & 1 \\
2 & & 0 & 0 & 0 \\
3 & & 1 & 0 & 0 \\
4 & & 5 & 1 & 0 \\
5 & & 5 & 11 & 11 \\
& Average & 4.1 & 4.9 & 4.7 \\
\hline
\end{tabular}

The one response received was non-committal: "Depends on the specific project-an ad hoc approach is probably best."

The last question was, "Are there other groups of administrators for whom you would recommend this service?" Responses were:

"All the Kendall Hall administrators" (Kendall Hall is the campus administration building) .

"I recommend the service remain limited to avoid wasting precious resources on some projects that may fall into the make-work category."

"Any person in an executive position."

Costs for the test were relatively low. Of the four types of direct costs that could be identified in advance (computer searching, photocopying, interlibrary loan charges, and mail and long-distance telephone) only the first two materialized during the test. Computer searching averaged $\$ 12.44$, and photocopying averaged $\$ 3.00$.

Staff time per question was about one hour (roughly estimated as 45 minutes of librarian time, 15 minutes of support staff time). Librarian time was calculated from initial consultation to presentation of results. The time taken to explain the purpose and scope of the test on the initial visit is not included in this, but would probably add about 15 minutes to that first visit.

There is not much likelihood of academic libraries passing salary costs along to their own administrators, but if they did it would add \$15-\$20 to the transaction cost, at current rates for an upper-range librarian and a middle-range paraprofessional.

Costs for supplies and other miscellaneous operating needs were negligible. Overhead and opportunity costs were not computed, but would be institution-specific.

Within this framework the total identifiable cost of providing the service appears to be about $\$ 30-\$ 35$ per question - probably very close to the cost of other types of in-depth library service offered on a limited scale.

On learning of this proposal to offer such a service, even in test mode, all the administrators personally expressed much gratitude and support to the Library for bringing it about. The survey results show that, with possibly one exception, their enthusiasm was still high after they had received the results. We would recommend that any academic library try such a service, using a small test like this one if necessary to assess the impact on the library. The results will probably be surprisingly positive in terms of the perceptions of the library by your institution's most influential single group. A more detailed review and analysis of this type of service is the subject of a longer article currently in progress. ${ }^{2}$

${ }^{2}$ Peter G. Watson and Rebecca Kellogg, "Information Support for Academic Administration: A New Role for the Library" (in progress). 